\title{
Power line routing and configuration as major drivers of collision risk in two bustard species
}

\author{
Ana Teresa Marques, Ricardo C. Martins, Joño Paulo Silva \\ Jorge M. PALMEIRIM and Francisco Moreira
}

\begin{abstract}
Collision with power lines is a major cause of mortality for many bird species. Understanding the biotic and abiotic factors that increase collision risk is therefore important for implementing mitigation measures to minimize mortality, such as power line rerouting or wire marking. Here, we used collision events registered during 2003-2015 along $280 \mathrm{~km}$ of transmission power lines in southern Portugal to analyse spatio-temporal patterns and collision risk factors in two sympatric, threatened, and collisionprone species: the great bustard Otis tarda and the little bustard Tetrax tetrax. The occurrence of collisions was not uniform across space and time, and variations could be explained by the species' ecological requirements, distribution patterns and behaviour. Although both species fly considerable distances between areas of suitable habitat, collisions were far more likely in power line sections with $>20 \%$ (for the little bustard) or $>50 \%$ (for the great bustard) of open farmland habitat in the surroundings. Power line configuration was also important: taller pylons and those with a higher number of wire levels posed a higher risk for both species. Wire marking had a small but significant effect for the little bustard, reducing collisions risk. There was, however, no similar effect for the great bustard, possibly a result of limited data. Mitigation measures should be implemented to prevent bustard collisions, including adequate route planning, ideally avoiding areas with $>20 \%$ of open habitat. Line configuration and wire marking are particularly important where such localities cannot be avoided and power lines cross areas with a high proportion of bustard habitat, including outside protected areas.
\end{abstract}

Keywords Anthropogenic mortality, birds, bustard, collision risk, mitigation, Otis tarda, Tetrax tetrax, transmission lines

\footnotetext{
Ana Teresa Marques* (Corresponding author, (D) orcid.org/0000-0003-3279643X) and Jorge M. Palmeirim (ID orcid.org/0000-0003-4734-8162) Centro de Ecologia, Evolução e Alterações Ambientais, Faculdade de Ciências, Universidade de Lisboa, 1749-016 Lisboa, Portugal

E-mail ateresamarques@gmail.com

Ricardo C. Martins* (D orcid.org/0000-0003-2540-8574), João Paulo Silva* (D) orcid.org/0000-0002-1956-5779) and FrancisCo MoreIRA* (DD orcid.org/ 0000-0003-4393-8018) Centro de Investigação em Biodiversidade e Recursos Genéticos, Laboratório Associado, Universidade de Lisboa, Lisboa, Portugal

*Also at: Centro de Investigação em Biodiversidade e Recursos Genéticos, Laboratório Associado, Universidade do Porto, Vairão, Portugal

Received 6 December 2018. Revision requested 23 January 2019.

Accepted 5 March 2019. First published online 14 February 2020.
}

Supplementary material for this article is available at doi.org/10.1017/So030605319000292

\section{Introduction}

Oollisions with power lines are an important source $\checkmark$ of anthropogenic mortality for birds (Bevanger, 1998; Drewitt \& Langston, 2008; Loss et al., 2015). In the USA, for example, tens of millions of birds are estimated to die annually in collisions with power lines (Loss et al., 2014). There is evidence of population-level effects for some threatened collision-prone species (e.g. Shaw et al., 2010, 2017; Marcelino et al., 2018).

The main strategies to prevent bird collisions with power lines include (1) power line route planning to avoid important areas of occurrence and flight paths, (2) choosing power line configurations with lower collision risk and (3) increasing wire visibility by attaching markers such as spirals or flappers (Bernardino et al., 2018). Wire marking is frequently used in areas of conservation importance for birds, although with variable or unknown effectiveness (Jenkins et al., 2010; Barrientos et al., 2012).

The planning and implementation of mitigation actions requires understanding of the biotic and abiotic drivers of bird collision with power lines. However, relatively little is known about such drivers (Loss et al., 2015), mainly because collision risk is species-specific and thus difficult to model. Furthermore, most published studies focus on individual sites, and assessments at a large spatial scale are rare (Silva et al., 2014). This could explain why some of the most commonly recommended practices in the installation of power lines are not supported by scientific evidence (Bernardino et al., 2018). One example is power line configuration: wire height, the number of wire levels and the spacing between them are assumed to influence the collision risk, but there is little scientific evidence to support this assumption (Bernardino et al., 2018).

Gruiformes, including bustards, are highly prone to collisions with power lines because of their morphological features and visual perception (Bevanger, 1998; Janss, 2000; Martin \& Shaw, 2010), and there are many studies on power lines and bustards (e.g. Janss \& Ferrer, 2000; Raab et al., 2011; Burnside et al., 2015; Mahood et al., 2016; Shaw et al., 2017). However, few have focused on identifying the factors that contribute to collision risk for this group. Collision risk has been modelled for the blue crane 


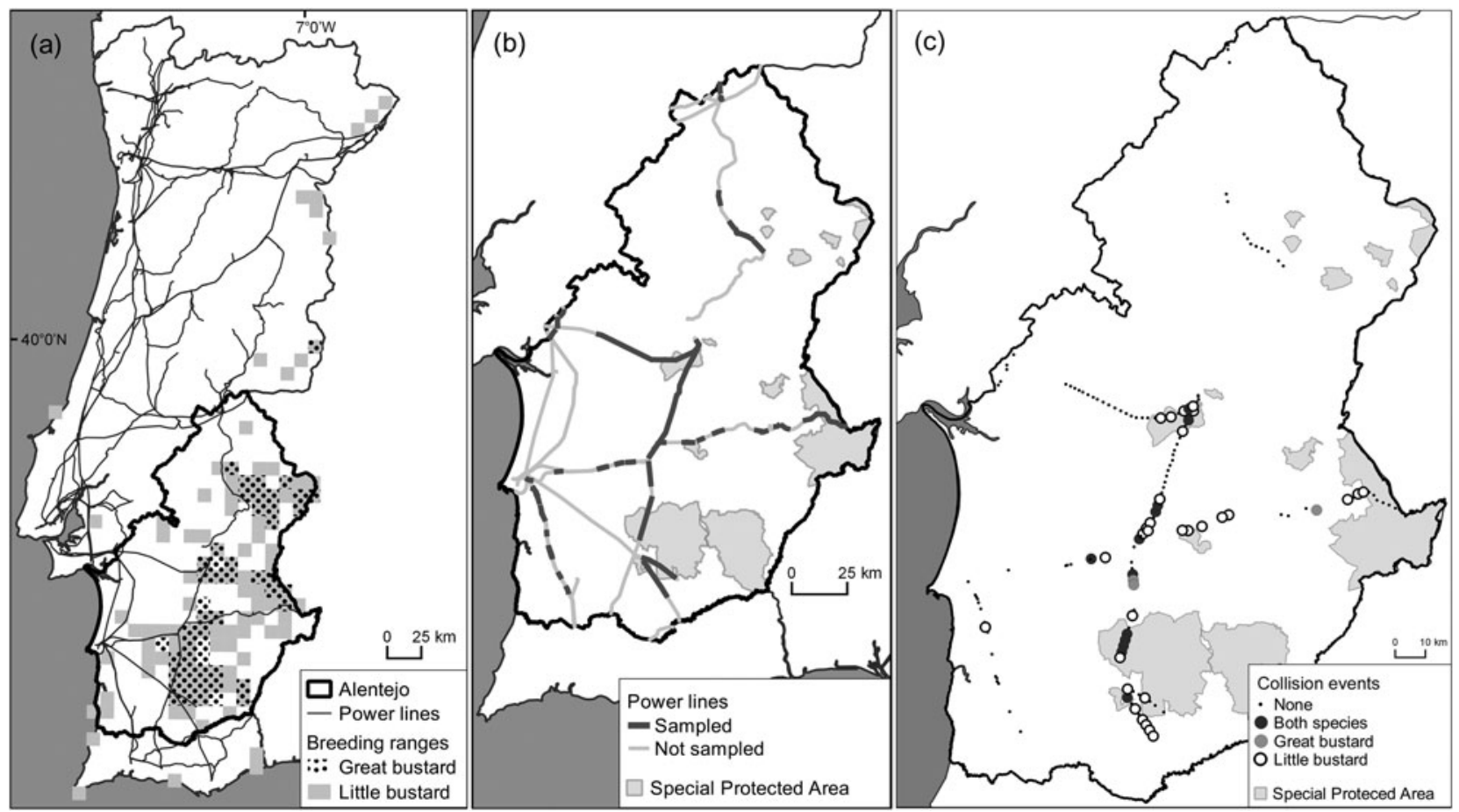

FIG. 1 (a) Great bustard Otis tarda and little bustard Tetrax tetrax breeding range (Equipa Atlas, 2008) and transmission (150-400 kV) power line network in Portugal. (b) Surveyed sections of the power line network and Special Protected Areas with open habitats in the study area, Alentejo. (c) Presence/absence of mortality events of the great and little bustard in each sampled power line section in Alentejo. For visualization purposes, the $2 \mathrm{~km}$ power line sections are represented by their central point.

Anthropoides paradiseus and Ludwig's bustard Neotis ludwigii in South Africa, using fatality events (Shaw et al., 2010, 2017). These models revealed some factors that put birds at risk but were unable to identify the location or configuration characteristics that make some power lines particularly dangerous. In Europe an alternative approach was deployed to assess collision risk for the little bustard Tetrax tetrax (Silva et al., 2014). This study did not utilize collision records but a spatially explicit risk model based on habitat suitability, population densities and flight behaviour.

In the Iberian Peninsula, the sympatric great bustard Otis tarda and little bustard are highly prone to collision with overhead wires. Both species are considered poor fliers because of their heavy bodies and relatively small wings (Rayner, 1988), and their eye morphology makes them blind in the direction of travel (Martin \& Shaw, 2010). Limited manoeuvrability and eyesight make species prone to collisions (Bernardino et al., 2018). The great bustard is categorized as Vulnerable on the IUCN Red List (BirdLife International, 2017). Collision with power lines is a main source of anthropogenic mortality for the species, and induces changes in its migratory patterns (Palacín et al., 2017). Migrant birds have a higher mortality rate from collisions compared to sedentary ones (21.3 vs $6.3 \%$ ), and an increase in the proportion of resident birds has been reported during a 15-year period (1997-2012) in Spain (Palacín et al., 2017). The little bustard is Near Threatened
(BirdLife International, 2017) and has experienced large population declines since 2000 (García de la Morena et al., 2017; Silva et al., 2018). The annual survival rate of adult little bustards in Iberia, which hosts the largest population in Western Europe (Iñigo \& Barov, 2010), is 67\%, the lowest known for any wild bustard species. Power lines are the main source of anthropogenic mortality for the species, with $3.4-3.8 \%$ of the Iberian population annually involved in collisions (Marcelino et al., 2018). Power lines are thus likely to have population-level effects on both species.

Great and little bustards use similar habitats and both make regional migrations, but differences in morphology and behaviour could result in distinct collision risk patterns and drivers. Here we aimed to identify and compare the main drivers of collision risk for these two sympatric species. We compiled data collected during 13 years in southern Portugal, along $28 \mathrm{o} \mathrm{km}$ of transmission power lines, to determine for both species (1) the spatial and temporal patterns of collision, and (2) the relative importance of land-cover type, technical features of power lines, and wire marking as determinants of collision risk. Based on the results we suggest improvements for mitigation measures targeting these species.

\section{Study area}

The $27,000 \mathrm{~km}^{2}$ Alentejo region in southern Portugal (Fig. 1a) is characterized by plains and low hills up to 1,000 m. Land 
use is dominated by agricultural areas (c. 40\%), mainly permanent crops such as olive groves or vineyards and open areas occupied by non-permanent crops and pastures (c. $47 \%$ of the agricultural areas). Forests (c. $20 \%$ ) are mainly silvo-pastoral sparse woodlands dominated by holm oak Quercus rotundifolia or cork oak Quercus suber (INE, 2011; DGT, 2014). The climate is typically Meso-Mediterranean and Thermo-Mediterranean, characterized by hot, dry and long summers and mild, wet winters (Rivas-Martínex et al., 2002).

Alentejo harbours the entire Portuguese breeding population of the great bustard (c. 1,150 birds; Pinto et al., 2005) and $90-95 \%$ of the little bustard's breeding population (c. 8,900 males; Silva et al., 2018). The main breeding areas of both species are inside Special Protected Areas (Fig. 1a,b), but key areas used during the post-breeding season and in winter are not protected (Silva \& Pinto, 2006; Silva et al., 2007, 2014). The Special Protected Area status requires the implementation of management actions that include the mitigation of bird collision risk, specifically through the installation of wire-marking devices in new power lines.

The total length of the transmission power line network in the region is $1,239 \mathrm{~km}$ (Fig. 1b), primarily 150 and $400 \mathrm{kV}$ power lines. Wires are marked in some sections, particularly inside Special Protected Areas. Wire-marking devices are generally installed on both earth wires, assembled in an alternated way, to produce a visual spacing effect, in profile, of $1.5-5 \mathrm{~m}$. The majority of marking devices are large $(30 \mathrm{~cm}$ diameter) white and red/orange spirals, but smaller $(10 \mathrm{~cm}$ diameter) grey or white and red/orange spirals and rotating flappers are also used.

\section{Methods}

\section{Data compilation}

We compiled data from the nine studies on bird collisions with transmission power lines conducted in Alentejo during 2003-2015, all promoted by Redes Energéticas Nacionais, the company managing the Portuguese transmission network. These studies included a national assessment of bird mortality at transmission power lines, two studies focusing on wire-marking effectiveness, performed by nongovernmental organizations and by the public administration, and six monitoring programmes of single power lines carried out within the scope of an environmental impact assessment processes (Supplementary Table 1).

A total of $280 \mathrm{~km}$ of power lines, c. $23 \%$ of the transmission grid in the region, were systematically surveyed at least once per season during the course of these studies. Sampling effort was uneven across studies (study duration was 12-67 months and intervals between sampling were 15-90 days;
Supplementary Table 1). Collision data also varied in spatial and temporal detail, with the lowest resolution data being the number of carcasses per $2 \mathrm{~km}$ power line section. Because of this variation in sampling effort and data resolution across studies, we divided the total sampled power line into 144 sections of c. $2 \mathrm{~km}$ each (mean 1,946 \pm SD $3.19 \mathrm{~m}$; range $755-2,767 \mathrm{~m}$ ) and used the presence/absence of mortality of each species per section in our analysis (except for the temporal analysis, where we used all available data; see next section). None of the studies reported malfunctioning of marking devices, such as devices fallen off the wire, flapper twist or colour changes.

\section{Seasonal and spatial patterns of collision}

We compiled the locations of power line sections with reported bustard mortality events for each species and estimated seasonal patterns, separately for power line sections inside and outside the Special Protected Areas network. The birds congregate in the protected areas during the breeding season, so we expected collision patterns to vary over time. Only studies with regular sampling at intervals of 15 or 30 days reported bustard fatalities with detailed temporal data, and therefore the seasonal data presented here result from a constant annual survey effort.

\section{Collision risk modelling}

To identify the main drivers of bustard collisions with power lines we selected variables representing habitat availability in the area surrounding the power lines, power line configuration, wire marking and survey effort (Table 1). Great and little bustard are grassland species with strict habitat requirements, typically occurring in open and flat or gently undulating landscapes (BirdLife International, 2017). Both are short distance migrants, performing seasonal movements of up to $260 \mathrm{~km}$ (great bustard) $/ 300 \mathrm{~km}$ (little bustard). The majority of birds ( $65 \%$ in the great bustard, $89-96 \%$ in the little bustard) move from their breeding grounds to areas with higher food availability during late spring and summer (Rocha, 2006; García de la Morena et al., 2015; Palacín et al., 2017; Alonso et al., 2019). Collisions are more frequent during the post-breeding and wintering seasons (Silva et al., 2014; Palacín et al., 2017), when bustards make most migratory movements. Collision events could thus be associated with the landcover types crossed during migrations, in addition to the habitats the birds use when not migrating. We extracted landcover information from the 2007 Carta de Ocupação do Solo (DGT, 2007) and combined different categories into three broad classes, which were probably stable during the study period: open farmland, forest and agroforestry (Table 1). We used the dominant land-cover type (in terms of total area) in 
TABLE 1 Description and summary statistics for the predictor variables used to assess the drivers of power line collision risk for the great bustard Otis tarda and little bustard Tetrax tetrax. Mean \pm SD and range are provided for continuous variables; frequency per class is presented for categorical variables ( $n=144$ sampled transects).

\begin{tabular}{|c|c|c|c|}
\hline Variable & Description & Mean $\pm \mathrm{SD} /$ Frequency & Range \\
\hline Open_Habitat & $\begin{array}{l}\text { Proportion of open farmland habitat in a } 5 \mathrm{~km} \text { buffer around the } \\
\text { power line section (DGT, 2007) }\end{array}$ & $0.43 \pm 0.19$ & $0.14-0.87$ \\
\hline D_Habitat & $\begin{array}{l}\text { Dominant habitat in a } 1 \mathrm{~km} \text { buffer around the power line section } \\
\text { (DGT, 2007): open farmland (land-cover categories according to } \\
\text { DGT, 2007: 2.1.1, 2.1.2, 2.3.1), forest }(3.1 .1,3.1 .2,3.1 .3,3.2 .4) \\
\text { \& agro-forestry }(2.4 .4)\end{array}$ & $\begin{array}{l}\text { Open: } 81 \\
\text { Forest: } 36 \\
\text { Agroforestry: } 27\end{array}$ & \\
\hline Configuration & $\begin{array}{l}\text { Power line configuration (Supplementary Fig. 1): small, hori- } \\
\text { zontal } 150 \mathrm{kV} \text {; medium, horizontal } 400 \mathrm{kV} \text {; large, vertical } 150 \text { or } \\
400 \mathrm{kV}\end{array}$ & $\begin{array}{l}\text { Small: } 77 \\
\text { Medium: } 36 \\
\text { Large: } 29\end{array}$ & \\
\hline Marking & Wire marker devices (presence/absence) & $\begin{array}{l}\text { Absent: } 90 \\
\text { Present: } 54\end{array}$ & \\
\hline Effort & $\begin{array}{l}\text { Total accumulated surveyed distance }(\mathrm{km}) \text { in all sampling visits } \\
\text { (length of power line section } \times \text { minimum number of samples) }\end{array}$ & $48.3 \pm 50.5$ & $4.6-265.5$ \\
\hline
\end{tabular}

a $2 \mathrm{~km}$ wide buffer strip around each power line section ( $1 \mathrm{~km}$ either side of the power line) as a surrogate of habitat availability in the vicinity of the line. Additionally, we measured the proportion of open farmland in a $10 \mathrm{~km}$ buffer surrounding each power line section ( $5 \mathrm{~km}$ either side) as an indicator of the availability of potentially suitable habitat in the area. We categorized power line sections according to three main configurations: (1) small configuration (low pylon height) and (2) medium configuration (medium pylon heights), both with conductor wires displaced horizontally and wires at two levels, and (3) large configuration, with conductor wires displaced vertically and wires at four levels, higher pylons, and larger distance between top and bottom wires (Supplementary Fig. 1). All three power line configurations have two earth wires above the conductors. We used a presence/absence variable for anti-collision devices (of any type) in each $2 \mathrm{~km}$ section. Finally, we included an indicator of survey effort (accumulated surveyed distance in all sampling visits; Table 1), to account for potential survey bias amongst power line sections.

We used Spearman's correlation coefficient and variance inflation factors to check for collinearity between explanatory variables (Zuur et al., 2009). Variance inflation factor values (all $<1.6)$ and pairwise correlation between explanatory variables (all $|r|<0.60$ ) were low and therefore we used all variables in the analysis.

We assessed the overall effect and relative importance of each explanatory variable with boosted regression trees (De'Ath, 2007), using the dismo package (Hijmans et al., 2016) in $R$ 3.3.1 (R Core Team, 2016), following the recommendations of Elith et al. (2008). Boosted regression trees is a non-parametric machine-learning method that fits a large number of simple classification or regression trees (models that relate a response to their predictors by recursive binary splits), with predictions combined to give robust response estimates (De'ath \& Fabricius, 2000; Elith et al., 2008).
The advantages of boosted regression trees include accommodation of missing values, ability to use both continuous and categorical predictor variables, immunity to the effects of extreme outliers, and the facility to fit interactions between predictors (Leathwick et al., 2006).

We generated one boosted regression trees model for each species, using presence/absence of mortality on power line sections as the response variable. As input parameters we used the Bernoulli family, a tree complexity of three (i.e. the complexity of variable interactions that may be fitted), a 0.0005 learning rate (the weight applied to individual trees) and a bag fraction of 0.8 (at each iteration, $80 \%$ of the data were drawn at random). Each model was built with a default 10-fold cross-validation (using the function gbm.step). When fitting initial models (Supplementary Fig. 2), some of the fitted functions generated had varying shapes without underlying ecological meaning. For example, the fitted function for the effects of the proportion of open habitat on the great bustard was variable for a large range of values. Additionally, it seemed that collision risk for this species was higher in the presence of wire marking. Such patterns often result from combinations or interactions of variables in specific geographical contexts that, in spite of having no ecological meaning, contribute to increased model fit (Leathwick et al., 2006; Elith et al., 2008). For example, the higher likelihood of great bustard collisions in the presence of wire marking is probably a result of the fact that most power lines that cross important areas for this species during the breeding season have been marked. Therefore, following Leathwick et al. (2006), we refitted the models by imposing monotonically increasing (for the proportion of open habitat and survey effort) or decreasing (for wire marking) constrained functions for some variables. Imposing monotonic trends reduces the total amount of deviance explained by the models but also decreases the likelihood of overfitting (Leathwick et al., 
2006; Jorda et al., 2015) and avoids falsely attributing explanatory power to some variables (Smith et al., 2013). We assessed model performance using the explained deviance (as a percentage of the null deviance), correlation and area under the receiver operator characteristic curve (AUC), through cross-validated statistics (Buston \& Elith, 2011).

We estimated the relative importance of each individual variable (as per cent contribution to the overall effect of all variables) in a model based on how often the predictor was selected and the improvement to the model as result of the selection (Buston \& Elith, 2011). We used the function $\mathrm{gbm}$. plot to build partial dependence plots and visualize the fitted functions from the boosted regression tree models. Important interactions between predictor variables were visualized using the gbm.interaction function.

Because of its stochasticity component, each boosted regression trees run provides slightly different results. Therefore, we performed 100 runs of gbm.step to estimate the minimum and maximum values for the fitted functions, the importance of variables and cross-validated measures of model performance (Fernandes et al., 2016).

We used spline correlogram plots with $95 \%$ pointwise confidence intervals calculated with 1,00o bootstrap resamples to check for spatial autocorrelation in model residuals (Bjørnstad \& Falck, 2001). We assumed that variable selection and parameter estimation were unbiased if there was no significant autocorrelation in model residuals (Rhodes et al., 2009). Correlograms were built with the function spline.correlog from the $R$ package $n c f$ (Bjørnstad, 2016).

\section{Results}

A total of 156 bustard fatality events were recorded in Alentejo during 2003-2015, 59 of great and 97 of little bustards. Most (75\%) fatality records were reported in two studies, one with a wide geographical range $(42 \%$ of the total number of power line sections surveyed in the region) corresponding to $35 \%$ of the fatality events (Neves et al., 2005), and a local study with an intensive survey effort (surveys at 15-day intervals for 29 months) that reported $40 \%$ of the events (Marques et al., 2007).

\section{Spatio-temporal collision patterns}

Collision events of both species exhibited a clustered spatial pattern (Fig. 1c). Great bustard collisions were concentrated in $15(10.4 \%)$ of the 144 power line sections, 12 of which also had little bustard fatalities. Little bustard collisions were more widely spread across the study area, occurring in a total of 42 sections $(29.2 \%)$.

The number of collision events varied throughout the year (Supplementary Fig. 3). Most of the carcasses of great bustards were found inside Special Protected Areas (73\%), whereas little bustards were more frequently found outside (55\%). Inside Special Protected Areas 65\% of the collision records of great bustards occurred during the autumn (September-November), with a second peak in spring (18\%, in April-May). Outside Special Protected Areas fatalities were concentrated during August-October (50\%). Little bustard collision events were registered all year. Inside Special Protected Areas fatalities peaked during the breeding season (c. $37 \%$, March-May) and during the postbreeding period ( $12 \%$ in July, and $39 \%$ during OctoberDecember). However, outside Special Protected Areas 62\% of little bustard collision events occurred during the dry months (July-September).

\section{Factors influencing bustard collisions}

The original (with unconstrained variables) boosted regression trees model for the great bustard (Supplementary Fig. 2a) explained $20.4 \%$ of the total deviance (AUC: $0.85 \pm$ SD 0.02; Pearson's correlation: $0.42 \pm$ SD 0.03). The proportion of open habitat was the most important predictor, with a trend for increased likelihood of collision for values $\geq 50 \%$. Survey effort, i.e. accumulated surveyed distance in all sampling visits (larger survey effort correlates with a higher likelihood of collisions being recorded, with a marked increase at c. $120 \mathrm{~km}$ accumulated sampling distance) and power line configuration (lower likelihood of collision in small configuration), ranked second and third, respectively. Wire marking and the dominant habitat in the close vicinity of the power line section had less influence on collision records. In the simpler model with the constrained variables (explained deviance: $15 \pm$ SD 2.1\%; AUC: $0.77 \pm$ SD 0.01; Pearson's correlation: $0.45 \pm$ SD 0.02 ) the order of variable importance was largely the same, although wire marking and dominant habitat near power lines were even less relevant (Fig. 2). Fitted functions of this model are shown in Fig. 2. The most important interactions between variables (Supplementary Fig. 4) suggest that the risk of collision with power lines in a small configuration, compared to other configurations, was much lower in regions with higher open habitat availability, and the effect of survey effort was particularly important in line sections with a higher proportion of open habitat.

For little bustard collisions, the boosted regression tree model with unconstrained variables explained $15.5 \%$ of the total deviance (AUC: $0.778 \pm$ SD o.01; Pearson's correlation: $0.46 \pm$ SD 0.02; Supplementary Fig. $3 \mathrm{~b}$ ) and was similar to the model with the constrained variables $(14.8 \pm$ SD $1.5 \%$ of explained deviance; AUC: $0.774 \pm$ SD 0.01 ; Pearson's correlation: $0.46 \pm$ SD 0.02). The proportion of open habitat was also the most important variable (although the shape of the fitted function suggested a continuously increasing effect, rather than a threshold effect as for the great bustard), 

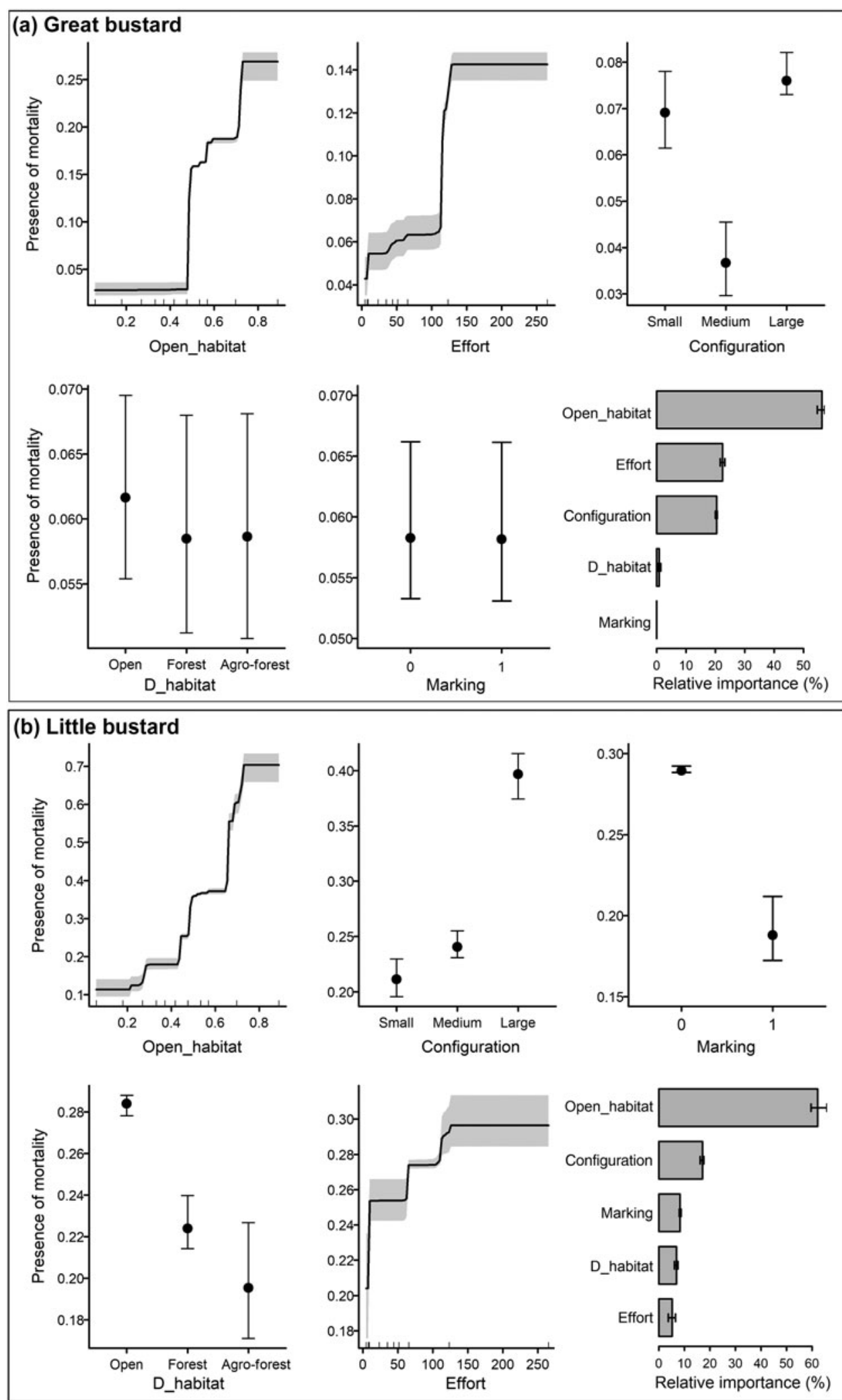

FIG. 2 Partial dependence plots (means and 95\% confidence intervals) and relative importance (per cent; means and $95 \%$ confidence intervals) for the predictor variables influencing the presence of mortality of (a) great bustards and (b) little bustards by collision with transmission power lines in Alentejo, Portugal. The models were fitted imposing a monotonic increase to the variables proportion of open habitat and survey effort, and a monotonic decrease to wire marking. See Supplementary Fig. 1 for details on small, medium and large configuration. Ticks along the $\mathrm{x}$-axis of a plot show the distribution of sites across the continuous variables, in deciles. Intervals for fitted functions and relative importance represent the range (minimum and maximum values) for a set of 100 runs.

followed by power line configuration (higher likelihood of collision with lines in large configuration; Fig. 2 \& Supplementary Fig. 2b). The likelihood of recording little bustard collisions decreased with wire marking and increased with survey effort. Interactions between variables suggest a higher risk of collision with wires in the large configuration at intermediate levels of open habitat availability compared to other power line configurations (Supplementary Fig. 5). 
For all models, there was no significant autocorrelation in model residuals (Supplementary Fig. 6).

\section{Discussion}

\section{Spatio-temporal collision patterns}

Both bustard species exhibited clustered spatial patterns of collision with power lines. These patterns are probably related to the species' distribution and abundance across the region, mainly determined by the availability of open habitats in flat areas with lower levels of human disturbance (e.g. Pinto et al., 2005; Silva et al., 2007; Equipa Atlas, 2008; Moreira et al., 2012). The influence of spatial distribution was also evident when comparing collision patterns: although there were high risk areas where collisions with power lines were recorded for both species, little bustard fatalities were spread more widely throughout the study area, and there were some localities where only collisions of little bustards were recorded. This could be explained by the larger and more widespread population of little bustard (Fig. 1a). Fatalities of both species were recorded inside and outside Special Protected Areas.

Temporal patterns in collisions may be explained by differences in flocking behaviour, activity and flight patterns. In the case of the little bustard, the peak of mortality during the post-breeding season is probably related to (1) the migratory movements that some individuals perform from the breeding grounds to areas with higher food resources (Silva et al., 2007; García de la Morena et al., 2015) and the use of stop-over sites in areas with poor habitat conditions during such periods (Alonso et al., 2019), (2) the increased distance travelled daily searching for food (Silva et al., 2014), (3) the higher frequency of flights at heights with an increased collision risk (Silva et al., 2014), and (4) the species' gregarious behaviour during this season. The collision pattern of the little bustard also varied across space: there was (1) a high number of collisions outside Special Protected Areas during summer (July-September), when birds leave their breeding grounds (Silva et al., 2007), (2) a peak of mortality during the autumn (October-December) within Special Protected Areas, probably associated with the return to the breeding grounds after the onset of rains (García de la Morena et al., 2015), and (3) a third mortality peak during the beginning of the breeding season inside Special Protected Areas, which coincides with the onset of the mating period (March-May) when males settle in breeding sites and females move between lekking areas.

Although the great bustard's annual distribution in Alentejo is not well known, there is evidence that it is influenced by the birds' behaviour and local movements, as in the little bustard. The majority of fatalities occurred in late summer and autumn (September-November), when a large number of birds leave their breeding grounds in search of areas with higher food availability and individuals tend to gather in larger flocks (Rocha, 2006). This temporal pattern also matches the higher frequency of flights crossing transmission power lines observed by Marques et al. (2007).

\section{Factors influencing collision risk}

The proportion of open farmland in the surrounding area was the main factor influencing collision risk in both species, suggesting that the presence of power lines within bustard habitat is the major collision driver. Collision events are less frequent during migratory journeys, when birds cross other habitat types, probably flying high over power line wires. The threshold for the proportion of open farmland that correlated with an increased collision risk differed between species: little bustard collisions were more likely when $>20 \%$ of the surrounding area was open habitat, whereas this threshold was $50 \%$ for the great bustard. This may reflect differences in habitat requirements between the species, with the great bustard requiring more open areas (Suárez-Seoane et al., 2002). The variable expressing the proportion of available habitat at a larger landscape scale (5 $\mathrm{km}$ buffer) was more important than the dominant habitat in the close vicinity of the power line ( $1 \mathrm{~km}$ buffer), although the latter was also relevant for the little bustard.

The configuration of the power line also influenced collision risk. For the little bustard, the large configuration with four levels of wires and a bigger collision risk area (larger distance between top and bottom wires), posed a higher risk than the small and medium configurations, both with just two levels of wires. Also, the comparison between the two horizontal configurations (with similar distance between top and bottom wires) showed that higher lines pose a greater risk to little bustards than lower ones. Although the effect of power line height on collisions is strongly dependent on flight altitude and may be speciesspecific, higher power lines and the vertical configuration generally pose a higher collision risk, as they are a larger barrier to birds in flight, which tend to gain altitude to fly over the obstacle rather than passing below (Luzenski et al., 2016; Murphy et al., 2016; Bernardino et al., 2018). This behaviour increases the likelihood of collision with the earth wires, which are thinner and less visible than the phase conductors (Bernardino et al., 2018). Although power line configuration has been suggested as a factor determining collision risk in several previous studies, our findings present the first robust evidence of this effect.

For the great bustard, the large configuration also appeared to be riskier than the small one, although the difference was not significant. However, the three configurations were not evenly represented in this species' range within the study area, and our dataset may thus not be adequate to test the effect of different power line configurations on great bustard collisions. Most transmission lines crossing 
important areas for the great bustard were of the small configuration and only a few had medium configuration, which could explain the absence of collision records involving this type of power line and the consequent predicted low collision risk.

Our findings also suggest that power line configuration may interact with habitat features: power lines with a large configuration posed a higher collision risk to little bustards in areas with intermediate levels of open habitat (c. 20$65 \%$ ), compared to the small and medium configurations. This may be because the little bustard tends to use areas with less suitable or fragmented habitats during the nonbreeding season (Silva et al., 2007), when the species also tends to fly at heights with higher collision risk (Silva et al., 2014).

The influence of power line configuration on bustard collision risk suggests that distribution power lines, usually much lower and with a smaller collision risk area, are less risky to these birds than transmission lines. However, the total length of the distribution grid is much larger: in Alentejo region there are c. $13,483 \mathrm{~km}$ of distribution power lines (Silva et al., 2014) vs 1,239 $\mathrm{km}$ of transmission lines. The distribution grid as a whole may thus represent an important mortality source despite the lower risk posed by individual lines.

Our results suggest wire marking devices have a significant but small effect in reducing collisions for the little bustard. Previous studies showed that wire marking devices have a limited effect on bustard species, and only large spirals were found to have some effect on the great bustard (Janss \& Ferrer, 1998; Barrientos et al., 2012). The data analysed in our study were insufficient to evaluate the effect of wire marking on the great bustard, as most of the transmission power lines crossing its main range had marking devices, making it difficult to separate habitat and mitigation effects. This could explain why the model fitted without imposing a monotonic trend suggested that power line sections marked with spirals posed a higher risk to the species.

\section{Implications for bustard conservation and power line monitoring}

The main determinant of collision risk for the great and little bustard is the proportion of open habitat in the area surrounding the power line. Therefore, the best mitigation measure for future transmission power lines is to avoid routing them through areas with large expanses of open farmland habitat. For existing lines, replacing the aerial wires with underground cabling would be the best solution to protect bustards in open farmlands (i.e. $>50 \%$ of open habitat), at least in Special Protected Areas that are important for both species. However, this is difficult to implement because of the high cost and potential legal and technical challenges
(Raab et al., 2012; Bernardino et al., 2018). Where underground cabling is not possible, we recommend the adoption of technical configurations with smaller pylons, a reduced number of wire levels (with fewer cables displaced vertically) and shorter distances between top and bottom wires. Additionally, all transmission lines crossing areas with $>_{20} \%$ open habitat in a $5 \mathrm{~km}$ buffer should have marking devices to increase their visibility. Although this mitigation measure appears to have only a small effect on these species it can reduce the number of fatalities. The choice of wire marking device should be based on the best evidence available, balancing the effectiveness and durability of available devices (Bernardino et al., 2018). Experimental designs focusing on bustard species, based on a before-after control-impact approach, should be used to identify the best devices for this bird group.

The high prevalence of mortality caused by collision with power lines in both bustard species (Marcelino et al., 2018; Palacín et al., 2017) indicates that reducing such anthropogenic mortality is likely to have a positive effect on their populations. Mitigation is particularly important for the little bustard, whose population has halved over the last 10-14 years (Silva et al., 2018).

Our results also show that the likelihood of finding a carcass increased with survey effort, particularly for the great bustard. Although these are larger birds and thus more likely to be detected during carcass surveys (Ponce et al., 2010), great bustard collisions are less common and a higher survey effort may be needed to detect them. The species occurs in lower numbers than the little bustard and its fatality pattern is temporally more scattered, particularly outside Special Protected Areas. Therefore, monitoring schemes focussing on bustards should include regular carcass surveys throughout the entire spring, summer and autumn.

Acknowledgements This research was funded by FCT (Fundação para a Ciência e a Tecnologia) and REN-Redes Energéticas Nacionais, in the scope of the REN Biodiversity Chair. ATM was funded by FCT doctoral grant SFRH/BD/100147/2014 and JPS with a contract DL57/2016. FM was funded by REN and FCT (IF/01053/ 2015), and RCM by a post-doctoral grant funded by REN and FCT, both under the REN Biodiversity Chair.

Author contributions Study design: ATM, JPS, JP, FM; data collection: ATM, RCM; data analysis: ATM, FM; writing: ATM, FM; revision: all authors.

\section{Conflicts of interest None.}

Ethical standards This research abided by the Oryx guidelines on ethical standards and did not require specific ethical or other approvals.

\section{References}

Alonso, H., Correia, R.A., Marques, A.T., Palmeirim, J.M., Moreira, F. \& Silva, J.P. (2019) Male post-breeding movements 
and stopover habitat selection of an endangered short-distance migrant, the little bustard Tetrax tetrax. Ibis, published online 12 January 2019.

Barrientos, R., Ponce, C., Palacín, C., Martín, C.A., Martín, B. \& Alonso, J.C. (2012) Wire marking results in a small but significant reduction in avian mortality at power lines: a BACI designed study. PLOS ONE, 7, e32569.

Bernardino, J., Bevanger, K., Barrientos, R., Dwyer, J.F., Marques, A.T., Martins, R.C. et al. (2018) Bird collisions with power lines: state of the art and priority areas for research. Biological Conservation, 222, 1-13.

Bevanger, K. (1998) Biological and conservation aspects of bird mortality caused by electricity power lines: a review. Biological Conservation, 86, 67-76.

BirdLife InTERNATIONAL (2017) IUCN Red List for Birds. birdlife.org [accessed 15 December 2017].

BjøRnstad, O.N. (2016) ncf: Spatial Nonparametric Covariance Functions. R package version 1.1-7. The Comprehensive R Archive Network. cran.r-project.org/web/packages/ncf/ncf.pdf [accessed 19 July 2019].

BjøRnStad, O.N. \& FALCK, W. (2001) Nonparametric spatial covariance functions: estimation and testing. Environmental and Ecological Statistics, 8, 53-70.

Burnside, R.J., Collar, N.J., Koshinin, M.A. \& Dolman, P.M. (2015) Avian powerline mortalities, including Asian houbara Chlamydotis macqueenii, on the Central Asian flyway in Uzbekistan. Sandgrouse, 37, 161-168.

Buston, P.M. \& ELITH, J. (2011) Determinants of reproductive success in dominant pairs of clownfish: a boosted regression tree analysis. Journal of Animal Ecology, 80, 528-538.

Dе’Aтн, G. (2007) Boosted trees for ecological modeling and prediction. Ecology, 88, 243-251.

De'Ath, G. \& Fabricius, K.E. (200o) Classification and regression trees: a powerful yet simple technique for ecological data analysis. Ecology, 81, 3178-3192.

DGT (Direção-Geral do Território) (2007) COS 2007-Carta de Ocupação do Solo 2007 para Portugal Continental. Direção-Geral do Território, Lisbon, Portugal.

DGT (Direção-Geral do Território) (2014) Uso e Ocupação do Solo em Portugal Continental. Avaliação e Cenário Futuros, Lisbon, Portugal.

Drewitt, A.L. \& Langston, R.H.W. (2008) Collision effects of wind-power generators and other obstacles on birds. Annals of the New York Academy of Sciences, 1134, 233-266.

Elith, J., Leathwick, J.R. \& Hastie, T. (2008) A working guide to boosted regression trees. Journal of Animal Ecology, 77, 802-813.

Equipa Atlas (2008) Atlas das Aves Nidificantes em Portugal (19992005). Instituto da Conservaçăo da Natureza e da Biodiversidade, Sociedade Portuguesa para o Estudo das Aves, Parque Natural da Madeira e Secretaria Regional do Ambiente e do Mar, Lisbon, Portugal.

Fernandes, P.M., Monteiro-Henriques, T., Guiomar, N., Loureiro, C. \& Barros, A.M.G. (2016) Bottom-up variables govern large-fire size in Portugal. Ecosystems, 19, 1362-1375.

García de la Morena, E.L., Morales, M.B., Bota, G., Silva, J.P., Ponjoan, A., SuÁrez, F. et al. (2015) Migration patterns of Iberian little bustards Tetrax tetrax. Ardeola, 62, 95-112.

García de la Morena, E., Bota, G., Mañosa, S. \& Morales, M. (2017) II Censo Nacional de sisón común: el dramático declive del bastión europeo de la especie. Boletín de Seguimiento de Aves de SEO/BirdLife, 2016, 30-33.

Hijmans, R.J., Phillips, S., Leathwick, J. \& Elith, J. (2016) dismo: Species Distribution Modeling. R package version 1. The Comprehensive R Archive Network.
INE (2011) Recenseamento Agrícola 2009-Análise dos Principais Resultados. Instituto Nacional de Estatística, Lisbon, Portugal.

Iñigo, A. \& B Arov, B. (2010) Action Plan for the Little Bustard Tetrax tetrax in the European Union. SEO/BirdLife and BirdLife International for the European Commission, Cambridge, UK.

Janss, G.F. \& Ferrer, M. (1998) Rate of bird collision with power lines: effects of conductor-marking and static wire-marking. Journal of Field Ornithology, 69, 8-17.

Janss, G.F. \& Ferrer, M. (200o) Common crane and great bustard collision with power lines: collision rate and risk exposure. Wildlife Society Bulletin, 28, 675-68o.

JANSs, G.F.E. (2000) Avian mortality from power lines: a morphologic approach of a species-specific mortality. Biological Conservation, 95, 353-359.

Jenkins, A.R., Smallie, J.J. \& Diamond, M. (2010) Avian collisions with power lines: a global review of causes and mitigation with a South African perspective. Bird Conservation International, 20, 263-278.

Jorda, H., Bechtold, M., Jarvis, N. \& Koestel, J. (2015) Using boosted regression trees to explore key factors controlling saturated and near-saturated hydraulic conductivity. European Journal of Soil Science, 66, 744-756.

Leathwick, J., Elith, J., Francis, M., Hastie, T. \& Taylor, P. (2006) Variation in demersal fish species richness in the oceans surrounding New Zealand: an analysis using boosted regression trees. Marine Ecology Progress Series, 321, 267-281.

Loss, S.R., Will, T. \& Marra, P.P. (2014) Refining estimates of bird collision and electrocution mortality at power lines in the United States. PLOS ONE, 9, e101565.

Loss, S.R., Will, T. \& Marra, P.P. (2015) Direct mortality of birds from anthropogenic causes. Annual Review of Ecology, Evolution, and Systematics, 46, 99-120.

Luzenski, J., Rocca, C.E., Harness, R.E., Cummings, J.L., Austin, D.D., LANDON, M.A. \& DWYER, J.F. (2016) Collision avoidance by migrating raptors encountering a new electric power transmission line. The Condor, 118, 402-410.

Mahood, S.P., Silva, J.P., Dolman, P.M. \& Burnside, R.J. (2016) Proposed power transmission lines in Cambodia constitute a significant new threat to the largest population of the Critically Endangered Bengal florican Houbaropsis bengalensis. Oryx, $52,147-155$.

Marcelino, J., Moreira, F., Mañosa, S., Cuscó, F., Morales, M.B., García De la Morena, E.L. et al. (2018) Tracking data of the Little Bustard Tetrax tetrax in Iberia shows high anthropogenic mortality. Bird Conservation International, 28, 509-520.

Marques, A.T., Rocha, P. \& Silva, J.P. (2007) Monitorização dos Efeitos da Linha de Muito Alta Tensão Ferreira do Alentejo/Ourique sobre Espécies Prioritárias, Mortalidade e Taxas de Voo. Instituto para a Conservação da Natureza, Lisbon, Portugal.

Martin, G.R. \& Shaw, J.M. (2010) Bird collisions with power lines: failing to see the way ahead? Biological Conservation, 143, 2695-2702.

Moreira, F., Silva, J.P., Estanque, B., Palmeirim, J.M., Lecoq, M., Pinto, M. et al. (2012) Mosaic-level inference of the impact of land cover changes in agricultural landscapes on biodiversity: a casestudy with a threatened grassland bird. PLOS ONE, 7, e38876.

Murphy, R.K., Dhyer, J.F., Mojica, E.K., McPherron, M.M. \& HARNESS, R.E. (2016) Reactions of sandhill cranes approaching a marked transmission power line. Journal of Fish and Wildlife Management, 7, 480-489.

Neves, J., Infante, S., Ministro, J. \& Brandão, R. (2005) Estudo sobre o Impacto das Linhas Eléctricas de Muito Alta Tensão na Avifauna em Portugal. [in Portuguese] Quercus Associação Nacional de Conservação da Natureza e SPEA Sociedade Portuguesa para o Estudo das Aves, Castelo Branco, Portugal. 
Palacín, C., Alonso, J.C., Martín, C.A. \& Alonso, J.A. (2017) Changes in bird-migration patterns associated with human-induced mortality. Conservation Biology, 31, 106-115.

Pinto, M., Rocha, P. \& Moreira, F. (2005) Long-term trends in great bustard (Otis tarda) populations in Portugal suggest concentration in single high quality area. Biological Conservation, $124,415-423$.

Ponce, C., Alonso, J.C., Argandoña, G., García Fernández, A. \& CARRASCO, M. (2010) Carcass removal by scavengers and search accuracy affect bird mortality estimates at power lines. Animal Conservation, 13, 603-612.

R CORE TEAM (2016) R: a Language and Environment for Statistical Computing. R Foundation for Statistical Computing, Vienna, Austria. r-project.org/ [accessed 19 July 2019].

Raab, R., Spakovszky, P., Julius, E., Schütz, C. \& Schulze, C.H. (2011) Effects of power lines on flight behaviour of the West-Pannonian great bustard Otis tarda population. Bird Conservation International, 21, 142-155.

RaAb, R., Schütz, C., Spakovszky, P., Julius, E. \& Schulze, C.H. (2012) Underground cabling and marking of power lines: conservation measures rapidly reduced mortality of West-Pannonian great bustards Otis tarda. Bird Conservation International, 22, 299-306.

RAYNER, J.M.V. (1988) Form and function in avian flight. In Current Ornithology (ed. R.F. Johnston), pp. 1-66. Springer, Boston, USA.

Rhodes, J.R., McAlpine, C.A., Zuur, A.F., Smith, G.M. \& Ieno, E.N. (2009) GLMM applied on the spatial distribution of koalas in a fragmented landscape. In Mixed Effects Models and Extensions in Ecology with R, pp. 469-492. Springer, New York, USA.

Rivas-Martínex, S., Diaz, T.E., Fernández-González, F., Izco, J., Loidi, J., Lousã, M. \& Penas, A. (2002) Vascular plant communities of Spain and Portugal. Itinera Geobotanica, $15,5-432$.

Rocha, P. (2006) Dinâmica Populacional e Distribuiçao da Abetarda no Baixo Alentejo-Relaçao com o Uso da Terra. Universidade
Técnica de Lisboa, Instituto Superior de Agronomia, Lisbon, Portugal.

Shaw, J.M., Jenkins, A.R., Smallie, J.J. \& Ryan, P.G. (2010) Modelling power-line collision risk for the Blue Crane Anthropoides paradiseus in South Africa. Ibis, 152, 590-599.

Shaw, J.M., Reid, T.A., Schutgens, M., Jenkins, A.R. \& Ryan, P.G. (2017) High power line collision mortality of threatened bustards at a regional scale in the Karoo, South Africa. Ibis, 16o, 431-446.

Silva, J.P. \& Pinto, M. (2006) Relatório Final da Acção 2 do Projecto Life Natureza (LIFEo2NAT/P/8476), Tetrax: Conservação do Sisão no Alentejo - Inventário dos Núcleos de Sisão no Alentejo. Instituto da Conservação da Natureza, Lisbon, Portugal.

Silva, J., Faria, N. \& Catry, T. (2007) Summer habitat selection and abundance of the threatened little bustard in Iberian agricultural landscapes. Biological Conservation, 139, 186-194.

Silva, J.P., Palmeirim, J.M., Alcazar, R., Correia, R., Delgado, A. \& Moreira, F. (2014) A spatially explicit approach to assess the collision risk between birds and overhead power lines: a case study with the little bustard. Biological Conservation, 170, 256-263.

Silva, J.P., Correia, R., Alonso, H., Martins, R.C., D’Amico, M., DELGADo, A. et al. (2018) EU protected area network did not prevent a country wide population decline in a threatened grassland bird. PeerJ, 6, e4284.

Smith, A.N., Duffy, C.A.J. \& Leathwick, J.R. (2013) Predicting the Distribution and Relative Abundance of Fishes on Shallow Subtidal Reefs Around New Zealand. Science for Conservation, 323, Publishing Team, New Zealand Department of Conservation, Wellington, New Zealand.

SuÁrez-Seoane, S., Osborne, P.E. \& Alonso, J.C. (2002) Large-scale habitat selection by agricultural steppe birds in Spain: identifying species-habitat responses using generalized additive models. Journal of Applied Ecology, 39, 755-771.

Zuur, A.F., Ieno, E.N., Walker, N., Saveliev, A.A. \& Smith, G.M. (2009) Mixed Effects Models and Extensions in Ecology with R. Springer New York, New York, USA. 